\title{
Finnish Biodiversity Information Facility - Improving the Taxonomic Coverage and Deepening the Information Content Through Collaboration
}

\author{
Kari M Lahti ${ }^{\ddagger}$, Liselott Sjodin Skarp ${ }^{\S}$ \\ ‡ Finnish Museum of Natural History LUOMUS, P.O.BOX 17, 00014 Helsinki University, Finland \\ $\S$ Swedish Species Information Centre (ArtDatabanken, SSIC), Swedish University of Agricultural Sciences (SLU), Uppsala, Sweden
}

Corresponding author: Kari M Lahti (kari.lahti@helsinki.fi), Liselott Sjodin Skarp (liselott.sjodin.skarp@slu.se)

Received: 15 Jul 2019 | Published: 17 Jul 2019

Citation: Lahti KM, Skarp LS (2019) Finnish Biodiversity Information Facility - Improving the Taxonomic Coverage and Deepening the Information Content Through Collaboration. Biodiversity Information Science and Standards 3 : e38274. https://doi.org/10.3897/biss.3.38274

\begin{abstract}
The Finnish Biodiversity Information Facility FinBIF (LINK: species.fi), operational since late 2016, is one of the more recent examples of comprehensive, all-inclusive national biodiversity research infrastructures. FinBIF integrates a wide array of biodiversity information approaches under the same umbrella. These include species information Fig. 1 (e.g. descriptions, photos and administrative attributes); citizen science platforms enabling recording, managing and sharing of observation data; an e-learning environment for species identification; management and sharing of restricted data among authorities; building a national DNA barcode reference library and linking it to species occurrence data; community-driven species identification support; large-scale and multi-technology digitisation of natural history collections; and IUCN Red Listing to conduct a periodic national assesment of the status of the threatened species.
\end{abstract}




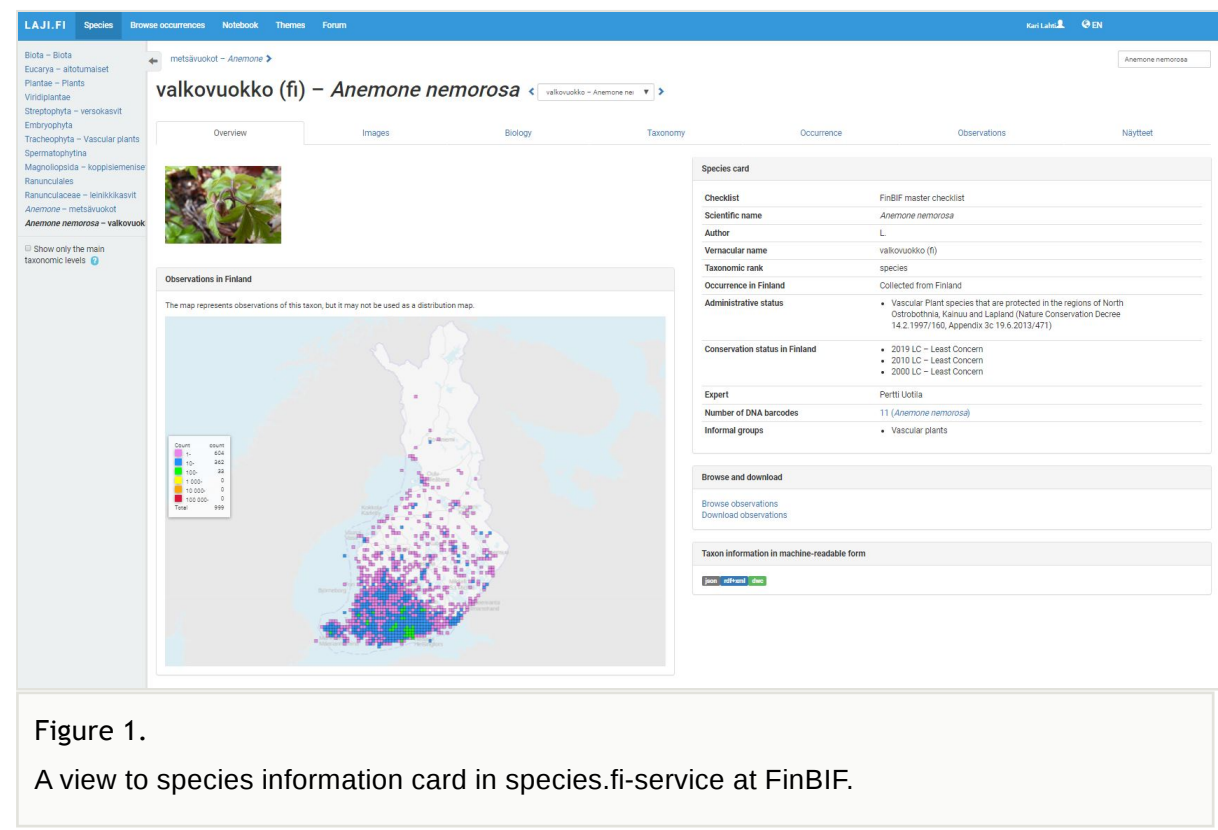

To improve the taxonomic coverage and the content of species information, FinBIF is starting a process to collaborate with the species information community at large, in order to collate already existing but not yet openly distributed information. This also means digitisation of information from analogue sources. In addition, the attempt is to join forces with Scandinavian counterparts, namely Artdatabanken (LINK: https://www. artdatabanken.se/) and Artsdatabanken (LINK: https://www.artsdatabanken.no/), for more efficient knowledge exchange within the countries sharing the same biogeographical region and thus similar species composition. The aim is also to reach politically high level agreement for deeper and wider commitment to collaborate in compiling, digitising and sharing relevant biodiversity information over the national borders.

\section{Keywords}

biodiversity informatics, species information, taxonomy

\section{Presenting author}

Kari Lahti

\section{Presented at}

Biodiversity_Next 2019 


\section{Funding program}

Finnish Research Infrastructures FIRI 